\title{
Sturge Weber Sendromlu Çocuk Hastalarda Radyolojik Bulgular
}

\section{Radiologic Findings of Sturge-Weber Syndrome in Pediatric Population}

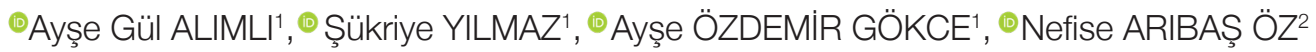

\author{
${ }^{1}$ S.B.Ü. Ankara Çocuk Sağlığı ve Hastalıkları Hematoloji Onkoloji SUAM, Radyoloji, Ankara, Türkiye \\ 2 S.B.Ü. Ankara Çocuk Sağlığı ve Hastalıkları Hematoloji Onkoloji SUAM, Çocuk Nöroloji Kliniği, Ankara, Türkiye
}

öz

Amaç: Çocuk hastalarda Sturge Weber Sendromu'nun (SWS) radyolojik bulgularını klinik bulgular eşliğinde tartışıp, SWS düșünülen hastaların erken dönemde tanı almasına katkı sağlamaktır.

Gereç ve Yöntemler: Hastanemizde Ocak 2010-Şubat 2019 tarihleri arasında SWS tanısı ile Beyin Bilgisayarlı Tomografi ya da Kranial Manyetik Rezonans Görüntüleme tetkiki yapılan 15 hasta çalışmaya dahil edilmiştir. Hastaların radyolojik tetkikleri iki pediatrik radyolog tarafından geriye dönük olarak değerlendirilmiştir. Hastaların demografik bilgilerine ve klinik bulgularına dosya arşivinden ulaşılmıştır.

Bulgular: 2 -185 ay aralığında (74.07 \pm 74.08 ay); 9 kız, 6 erkek hasta değerlendirildi. En sık başvuru yakınması nöbet (\%40) ve yüzde leke (26.66)'dı. Bir hastada bilateral olmak üzere toplamda dokuz hastada (\%60) SWS ile uyumlu radyolojik bulgu izlendi. Bu hastalardan kontrastlı tetkiki olan 7 hastada(\%100) leptomeningeal kontrastlanma ve manyetik duyarlı MRG tetkiki mevcut olan 7 hastada (\%100) ve BT tetkiki olan 2 hastada kalsifikasyon alanları mevcuttu. Fokal tutulumu olan bir hasta dişında tüm hastalarda transmedüller ve kortikal venlerde belirginleşme izlendi. Patolojik hemisferde ADC değerlerinde azalma mevcuttu. Hiçbir hastada akselere myelinasyon/beyaz cevher inversiyonu, diffüzyon kısıtlaması saptanmadı.

Sonuç: SWS nadir sporadik nörokutanöz bir sendrom olup klinik ve radyolojik olarak tipik bulguları vardır. Kontrastı MRG pial anjiomların tanısında en duyarlı yöntem olmakla birlikte manyetik duyarlı MRG kalsifikasyonların ve belirginleşmiş venöz kollaterallerin saptanmasında katkı sağlayabilir.

Anahtar Sözcükler: Çocuk, Epilepsi, MRG, Nöroradyoloji, Manyetik duyarlı MRG

\section{ABSTRACT}

Objective: To evaluate the radiological and clinical findings of Sturge Weber Syndrome in pediatric patients in the light of literature data and to contribute to the early diagnosis of SWS, in patients especially with facial port wine birthmark.

Material and Methods: Fifteen patients who underwent Cranial Computed Tomography or Magnetic Resonance Imaging with the diagnosis of SWS in our hospital; between January 2010 and February 2019 were included in this study. Radiologic examinations of the patients were evaluated retrospectively by two experienced pediatric radiologists in a concensus reading. Demographic information and clinical findings were obtained from the medical records.

Results: The patients' age ranged from 2 and 185 months (74.07 \pm 74.08 months); 9 female and 6 male patients were evaluated. The most common presenting symptoms were seizure (40\%) and facial port wine birthmark (26.66\%). Radiological findings compatible with SWS were observed in nine patients (60\%) and one of was bilateral. 7 patients had leptomeningeal enhancement and 8 patients had calcification areas. Transmedullary and cortical veins were observed in all patients except one patient with focal involvement. ADC values were decreased on pathological areas compared to normal hemisphere. None of the patients had accelerated myelination / white matter inversion or diffusion restriction.

Conclusion: SWS is a rare sporadic neurocutaneous syndrome with typical clinical and radiological findings. Although contrast-enhanced MRI is the most sensitive method in the diagnosis of pial angiomas, susceptibility-weighted imaging may contribute to the detection of calcifications and prominent venous collaterals.

Key Words: Child, Epilepsy, Magnetic Resonance, Neuroimaging, Susceptibility-weighted angiography 


\section{GiRiş}

Sturge Weber Sendromu (SWS, ensefalotrigeminal anjiomatozis) porto şarabı lekesi olarak adlandırılan trigeminal sinirin oftalmik dalı trasesinde fasiyal kapiller malformasyon, ipsilateral pial leptomeningeal anjiom ve ipsilateral glokom ile karakterize nadir bir konjenital nörokutanöz sendromdur $(1,2)$. SWS'da en sık GNAQ (guanine nucleotide-binding protein alpha-q) geninde c.548G $>$ A (p.R183Q) somatik mutasyonu izlenmektedir ve mutasyon zamanı hastalığın şiddetini belirlemektedir $(1,3,4)$.

SWS'nun üç alt tipi vardır. Tip 1'de deri ve nörolojik bulgular birlikte izlenirken, tip 2 nörolojik bulgular olmadan deri bulguları ve tip 3 deri bulguları olmadan nörolojik bulgular ile karakterizedir. Glokom genellikle tip 3 de beklenmezken, tip 1 ve tip 2 ile birliktelik gösterir En sık klinik bulgu nöbettir (\%75-85) ve genellikle ilk bulgu olup hastaların \%75'inde bir yaşından önce olmak üzere sıklıkla 2 yaş altında bulgu verir. Hastaların diğer başvuru nedenleri hemiparezi, inme benzeri ataklar, görme alanı bozuklukları, mental retardasyondur (1,2,5-8.)

SWS yüzün üst yarısında, trigeminal sinir trasesinde izlenen porto şarabı lekesi nedeni ile sıklıkla klinik olarak akla gelirken radyolojik bulgularla da tanı desteklenir. Günümüzde SWS tanısında standart kabul edilen kontrastlı T1 ağılıklı sekanslarda leptomeningeal kontrastlanma anjiomun direk bulgusudur ancak erken dönemde izlenmeyebilir. İpsilateral koroid pleksusta genişleme, serebral atrofi ve beyaz cevherin sinyal inversiyonu (T2A hipointens, T1 A hiperintens beyaz cevher) leptomeningeal anjiomun indirek bulgularıdır $(1,7,9)$. Ek olarak leptomeningeal anjiom izlenen düzeyde tren rayı şeklinde giral patern gösteren kortikal kalsifikasyonlar, atrofi, ipsilateral koroid pleksusta genişleme, paranazal sinüslerde ve mastoid hücrelerde ventriküler dilatasyon, kalvaryal kalınlaşma, paranazal sinüslerde, mastoid hücrelerde genişleme; pial anjiomlar düzeyinde medüller ve subependimal venlerde dilatasyon ve kollateral venöz yapılar izlenir. Radyolojik bulgular arasında SWS için en spesifik bulgu leptomeningeal kontrastlanma iken giral kalsifikasyon, atrofi ve ipsilateral koroid pleksusta genişleme de diğer en yaygın radyolojik bulgulardır $(5,10,11)$.

Bu çalışmanın amacı SWS radyolojik bulgularını klinik bulgular eşliğinde tartışıp, özellikle porto şarabı lekesi izlenen ve SWS düşünülen hastaların erken dönemde tanı almasına katkı sağlamaktır.

\section{GEREÇ VE YÖNTEMLER}

Bu çalışma için T.C. Sağlık Bilimleri Üniversitesi, Ankara Çocuk Sağlığı ve Hastalıkları Hematoloji Onkoloji Eğitim ve Araştırma Hastanesi klinik araştırmalar etik kurulundan 2019-169 tarih ve sayılı etik kurul onayı alındı. Hastanemiz arşivinde Ocak 2010-Şubat 2019 tarihleri arasında Beyin Bilgisayarlı Tomografi (BT) ve Kranial Manyetik Rezonans Görüntüleme (MRG) raporlarında ya da klinik istemlerinde Sturge ve Weber kelimeleri geçen hastalar sırasıyla tarandı. Sturge Weber Sendromu ön tanısı ile Beyin BT ve Kranial MRG tetkiki yapılan ya da radyoloji tetkikleri ile SWS düşünülen hastalar geriye dönük olarak tekrar değerlendirildi. Toplam 20 hastanın PACS ta bulunan radyolojik tetkikleri iki pediatrik radyolog tarafından (12 yıl radyoloji-5 yıl çocuk radyolojisi deneyimi olan A.G.A. ve 9 yıl radyoloji-4 yll çocuk radyolojisi deneyimi olan A.Ö.G.) retrospektif olarak incelendi ve tıbbi dosyaları pediatrik nörolog tarafından (N.A.Ö.) tarandl.

MRG incelemeleri Optima MR450 w marka 1.5 Tesla GE MR (Milwaukee, Wisconsin, USA) ve 1.5 Tesla Philips MR (Achieva; Philips Healthcare, Best, The Netherlands) cihazında çok kanallı kafa sarmalı kullanılarak çekildi. BT incelemeri 16 kesitli cihaz ile (Toshiba America Medical Systems), (100-120 kV; kesit kalınlığı $\leq 2$ mm; matriks 512×512 piksel; gantry açısı $0^{\circ}$ ) gerçekleştirildi. Tüm MR görüntülemeleri aksiyel spin-eko T1 ağırlıklı (TR/TE: 400-500/10-30 ms), aksiyel fluid-attenuated inversion recovery(FLAIR) (TR/TE: 9000-10000/100-110 ms), aksiyel ve koronal T2 ağırlıkı(TR/TE: 4000-6000/90-110 ms), aksiyel manyetik duyarlık (SWAN; GRE) sekansları, diffüzyon ağırlıklı görüntüleme (DAG; $b=0$ ve $B=1000$ ) ve $A D C$ haritası (Görünüşteki Difüzyon Katsayısı = Apparent diffusion coefficient) ile elde edildi. Görüntülerin kesit kalınlığı 3 boyutlu T1 ağırıklı görüntülemede $1 \mathrm{~mm}$, diğer sekanslara ait görüntülerde ise 3 mm'di. Ayrıca 11 hastada intravenöz gadolinyum enjeksiyonu sonrasında en az iki (aksiyel, koronal) planda T1 ağırlıklı sekanslar elde edildi. Beş hastaya TOF (time of flight) MR Anjiografi tetkiki yapıldı. Gereklilik halinde sedasyon için kloral hidrat (30-50 mg/kg, maksimum 1 gr) kullanıldı.

Olguların yaş (hastanemizdeki ilk radyolojik tetkik tarihindeki), cinsiyet, başvuru yakınması, fizik muayene bulguları, nihai tanıları sistemde var olan dosyalarından tekrar değerlendirildi. Radyolojik tetkiklerinde lezyon varlığı, yerleşim yeri (hemisfer ve lob olarak), koroidal hemanjiom, kalsifikasyon, kortikal atrofi, beyaz cevherin sinyal inversiyonu, kalvaryal kalınlaşma, ventriküler dilatasyon, koroid pleksusta genişleme, eşlik eden venöz anomali-arteriovenöz malformasyon-dural arteriovenöz fistül, medüller/subependimal venlerde dilatasyon, paranazal sinüslerde/mastoid hücrelerde genişleme, küçük hemikranyum varlığı belirtildi. Her iki hemisferde myelinasyon süreci arasında fark olup olmadığı incelendi. Lezyonların T1, T2, FLAIR, SWAN, DAG, ADC ve kontrast sonrası elde edilen görüntülerde; TOF (time of flight) MR Anjiografi tetkikinde sinyal özelliği ya da varsa eşlik eden ek bulgu kaydedildi.

Çalışmaya dahil edilen olguların verileri SPSS for Windows version 15 istatistik paket programı kullanılarak değerlendirildi. Tanımlayıcı istatistiklerde ortalama, maksimum ve minimum değerler ile birlikte yüzdelik dağılımlar belirlendi ve değişkenlik ölçütü ortalama \pm standart hata olarak verildi. 


\section{BULGULAR}

Radyoloji raporlarında'Sturge' kelimesi yer alan 16 hasta ve 'Weber' kelimesi yer alan 20 hasta tespit edildi. İki liste birleștirildi ve örtüşen isimler çıkartılıktan sonra toplamda 20 hasta ismine ulaşıldı. Bir hastanın kranial MR ya da BT tetkiki olmadığı için (ekstremite MR tetkiki vardı); serebral palsi/epilepsi ön tanılı bir hastada ve dilate kardiyomiyopati öyküsü olan bir hastada da nörolog ve iki pediatrik radyolog tarafından SWS düşünülmediği için; iki hastanın nihai tanısı SWS olmadığı için çalıșma dışı bırakıldı. Pediatrik nörolog/radyolog tarafindan SWS tanısı konulan 15 hasta çalışmaya dahil edildi.
Toplamda 2 -185 ay aralığında ( ortalama yaşıstandart sapma $74.07 \pm 74.08$ ay); 9 kIz (\%60) 6 erkek (\%40) 15 hasta değerlendirildi. En sık başvuru yakınması nöbet (\%40) ve yüzde leke (\%26.66)'di. Hastaların \%40'ı iki yaşından küçüktü, 2 hastada glokom tespit edildi. Elektroensefalografi (EEG) yapıımıș olan 5 hastanın birinde sağ frontotemporal bölgede (hasta no 2), birinde ise (hasta no 11) karșı hemisfere de yayılan sağ hemisferde jeneralize epileptik bozukluk tespit edildi. Çalışmaya dahil edilen olguların demografik ve klinik bulguları ile var olan radyolojik tetkikleri Tablo I de verildi.

Kranial görüntülemede patolojik bulgu saptanan 1 hastanın sadece BT tetkiki, 1 hastanın BT ve MR tetkiki, 7 hastanın

Tablo I: Hastaların demografik ve klinik özellikleri ile var olan radyolojik tetkikleri.

\begin{tabular}{|c|c|c|c|c|c|c|c|c|c|c|}
\hline Hasta & $\begin{array}{l}\text { Başvuru } \\
\text { Şikayeti }\end{array}$ & Öntanı & Fizik Muayene Bulguları & Cinsiyet & $\begin{array}{l}\text { Yaş } \\
\text { (ay)* }\end{array}$ & MRG† & $\begin{array}{c}\text { Kontrastlı } \\
\text { MRG }\end{array}$ & $\begin{array}{l}\text { TOF } ¥ \text { MR } \\
\text { Anjiografi }\end{array}$ & BT § & $\begin{array}{c}\text { Kontrastlı } \\
\text { BT }\end{array}$ \\
\hline 1 & SWS \| & SWS & Sol yüzde hemanjiom & K $\|$ & 4 & + & $\varnothing$ & $\varnothing$ & $\varnothing$ & $\varnothing$ \\
\hline 2 & Nöbet & SWS, nöbet & $\begin{array}{l}\text { Sağ yüzde hemanjiom, } \\
\text { Sağ üst ekstemitede } \\
\text { hemiparezi, } \\
\text { Sağ elde ve kolda atrofi, } \\
\text { Mental-motor gerilik }\end{array}$ & $E^{* *}$ & 5 & + & + & $\varnothing$ & $\varnothing$ & + \\
\hline 3 & Başdönmesi & $\begin{array}{l}\text { SWS?, } \\
\text { başdönmesi }\end{array}$ & Sol yüzde hemanjiom & K & 185 & + & $\varnothing$ & $\varnothing$ & $\varnothing$ & $\varnothing$ \\
\hline 4 & Nöbet & SWS, nöbet & Sağ yüzde hemanjiom & $E$ & 64 & + & $\varnothing$ & $\varnothing$ & $\varnothing$ & $\varnothing$ \\
\hline 5 & Yüzde leke & $\begin{array}{l}\text { Sol yüzde } \\
\text { hemanjiom }\end{array}$ & Sol yüzde hemanjiom & E & 2 & + & $\varnothing$ & + & $\varnothing$ & $\varnothing$ \\
\hline 6 & Nöbet & Nöbet & $\begin{array}{l}\text { Sağ tarafta hafif hemiparezi } \\
\text { (hemanjiom olmadığı } \\
\text { belirtilmiş) }\end{array}$ & K & 129 & + & + & + & $\varnothing$ & $\varnothing$ \\
\hline 7 & Nöbet & Fokal nöbet & Normal & E & 8 & + & + & + & $\varnothing$ & $\varnothing$ \\
\hline 8 & SWS & SWS & $\begin{array}{l}\text { Hemanjiom ( taraf,lokalizasyon } \\
\text { belirtilmemiș) }\end{array}$ & K & 16 & + & + & $\varnothing$ & $\varnothing$ & $\varnothing$ \\
\hline 9 & Yüzde leke & $\begin{array}{l}\text { Sol yüzde } \\
\text { hemanjiom }\end{array}$ & Sol yüzde hemanjiom & E & 35 & + & + & $\varnothing$ & $\varnothing$ & $\varnothing$ \\
\hline 10 & Nöbet & Nöbet & $\begin{array}{l}\text { Sol yüzde, sol kolda } \\
\text { hemanjiom, } \\
\text { Sağ üst ekstremitede } \\
\text { hemiparezi , sağ elde atrofi }\end{array}$ & K & 184 & + & + & + & $\varnothing$ & $\varnothing$ \\
\hline 11 & Yüzde leke & $\begin{array}{l}\text { Yüzde leke, } \\
\text { nöbet }\end{array}$ & Sağ yüzde hemanjiom & K & 7 & + & + & $\varnothing$ & $\varnothing$ & $\varnothing$ \\
\hline 12 & Yüzde leke & $\begin{array}{l}\text { Sol yüzde } \\
\text { hemanjiom }\end{array}$ & Sol yüzde hemanjiom & K & 137 & + & + & $\varnothing$ & $\varnothing$ & $\varnothing$ \\
\hline 13 & Nöbet & SWS, nöbet & $\begin{array}{l}\text { Solda hemiparezi, } \\
\text { Hemanjiom belirtilmemiş }\end{array}$ & K & 122 & + & + & + & $\varnothing$ & $\varnothing$ \\
\hline 14 & Başağrısı & $\begin{array}{l}\text { Başağrısı, sol } \\
\text { frontal } \\
\text { hemanjiom }\end{array}$ & Sol frontal hemanjiom & K & 185 & + & $\varnothing$ & $\varnothing$ & $\varnothing$ & $\varnothing$ \\
\hline 15 & Belirtilmemiş & $\begin{array}{l}\text { Metabolik } \\
\text { hastallk? }\end{array}$ & Belirtilmemiş & E & 28 & $\varnothing$ & $\varnothing$ & $\varnothing$ & + & $\varnothing$ \\
\hline
\end{tabular}

*Yaş ; radyoloji tetkiki sırasındaki yaş (ay), †MRG; Manyetik Rezonans Görüntüleme, ¥TOF MR Anjiografi; Time of Flight Manyetik Rezonans Anjiografi, \$BT; Bilgisayarlı Tomografi, /|SWS; Sturge Weber Sendromu, ף|K; kIz, ${ }^{* * E ;}$ erkek 
Tablo II: Sturge-Weber sendromlu hastaların radyolojik bulguları.

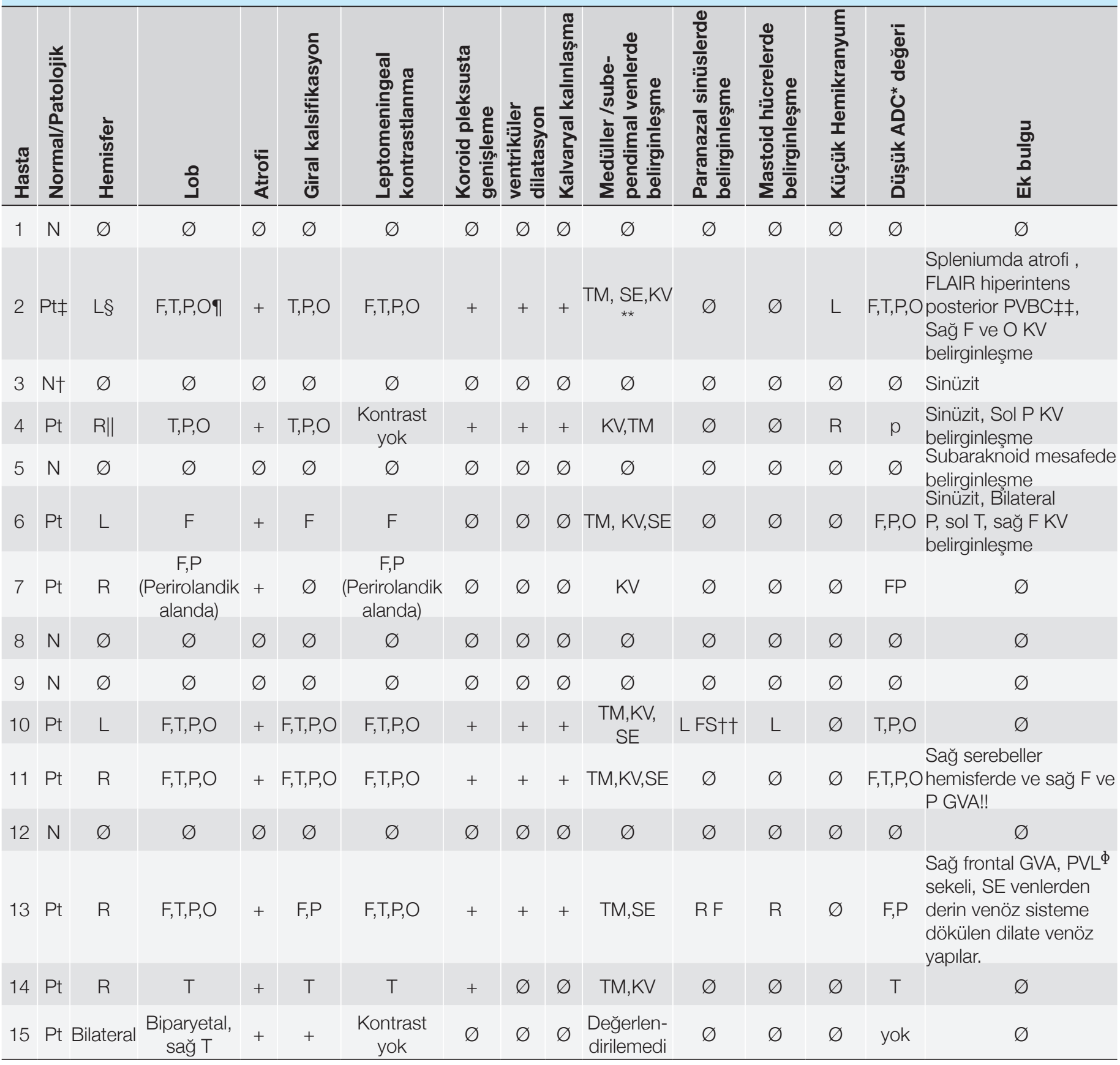

*ADC; Görünüşteki Difüzyon Katsayısı = Apparent diffusion coefficient, +N; Normal, ¥ Pt; Patolojik, §L; Sol, I/ R; Sağ, I F; Frontal, T; Temporal, P; Parietal, O; Oksipital, ** TM; Transmedüller venler, SE, subependimal venler, KV; kortikal venler, ††FS; Frontal sinuS, ¥¥PVBC; periventriküler beyaz cevher, !!GVA; Gelişimsel venöz anomali, ${ }^{\Phi} \boldsymbol{P V L}$; Periventriküler lökomalazi

ise kranial MRG tetkiki vardı. İki pediatrik radyolog birbirinden bağımsız olarak hastaları değerlendirdi; radyolojik bulgularda \%100 örtüşme vardı. 6 hastada (\%40) SWS düşündürür radyolojik bulgu saptanmadı. Bir hastada bilateral olmak üzere toplamda dokuz hastada (\%60) SWS ile uyumlu radyolojik bulgu izlendi (Tablo II). Kontrastlı tetkiki olan 7 hastada(\%100) leptomeningeal kontrastlanma saptandı. Manyetik duyarlı MRG tetkiki mevcut olan 8 hastanın 7'sinde manyetik duyarlı sekanslarda hipointens olarak belirginleșen kalsifikasyon alanları, perirolandik alanda fokal lezyonu olan bir hasta dışında (hasta no 7) transmedüller ve kortikal venlerde belirginleşme (\%87.5), 5 hastada (\%62.5) subependimal venlerde belirginleşme izlendi (Şekil 1,2). Altı hastada kortikal venlerden derin venöz sisteme uzanan belirginleşmiş venöz yapılar izlendi. İki hastada (hasta no 6 ve 14) kalsifikasyon alanları sadece manyetik duyarlı sekanslarda seçilebildi. Ek bulgu olarak iki hastada gelişimsel venöz anomali mevcuttu, bir hastada periventriküler lökomalazi (PVL) sekeli ile uyumlu radyolojik bulgular ve bir hastada posterior 
periventriküler beyaz cevherde spesifik olmayan T2 hiperintens sinyal değişiklikleri ile birlikte spleniumda atrofi saptandı. Bir hastada sol gözde diffüz koroidal hemanjiom mevcuttu (Şekil 1). Hiçbir hastada akselere myelinasyon/beyaz cevher inversiyonu saptanmadı. Hastaların hepsinde DAG, 4 hastada TOF MR Anjiografi tetkiki mevcuttu; ancak patolojik bulgu izlenmedi. Hastaların ADC haritalarında patolojik hemisferde ADC değerleri karşı hemisfere kıyasla düşüktü (Şekil 2).

Klinik dosyalarında iki hastada (\%13.33) ciltte leke varlığı/ yokluğu belirtilmemişti, bir hastada (\%6.66) ise leke varlı̆ı belirtilmişken lokalizasyonu belirtilmemişti. İki hastada (\%13.33) ciltte leke yoktu, 7 hastada sol yüzde (\%46.66), 3 hastada (\%20) ise sağ yüzde anjiom mevcuttu. Bir hasta dışında (hasta no 3) yüzde anjiom ile uyumlu porto şarabı lekesi olan tüm hastaların radyolojik bulguları ipsilateral hemisferdeydi.

SWS ile uyumlu radyolojik bulguları olan iki hastada (\%13.33) yüzde anjiom mevcut değildi (tip 3 SWS); iki hastada (\%13.33) anjiom varlığı belirtilmemişti; 5 hastada (\%33.33) ise yüzde anjiom mevcuttu (Tip 1 SWS). Kranial MRG tetkikleri normal olan 6 olgunun (\%40) da yüzde anjiomu vardı ( tip 2 SWS). Radyolojik bulgusu olan olguların fizik muayenelerinde; 4 hastada (\%44.44) hemiparezi, 2 hastada (\%22.22) üst ekstremitede atrofi ve bir hastada (\%11.11) mental-motor gerilik tespit edildi.

\section{TARTIŞMA}

SWS nadir sporadik nörokutanöz bir sendrom olup klinik ve radyolojik olarak tipik bulguları vardır. Kontrastlı MRG pial anjiomların tanısında en duyarlı yöntem olmakla birlikte manyetik duyarlı MRG kalsifikasyonların ve belirginleşmiş venöz kollaterallerin saptanmasında katkı sağlayabilir.

SWS sıklikla tek taraflıdır (\%85), daha nadir olarak bilateral de gözükebilir. Canpolat ve ark.(12) yayınladıkları 11 hastalık seride bizim çalışmamızda olduğu gibi sadece bir olguda bihemisferik tutulum bildirmişlerdir. SWS sıklıkla 2 yaş altında epilepsi ile tanı almaktadır ve nöbet sıklıkla ilk başvuru şikayetidir. Ancak nadir de olsa bir hastamızda olduğu gibi adolesan çağda başağrısı gibi beklenmedik semptomlarla da karşımıza çıkabilir. Bu çalışmada hastaların \%40' iki yaşın altındaydı ve iki yaş altındaki hastaların sadece yarısı nöbet ile tanı aldı. Bu bulgu bu çalışmadaki hasta sayısının kısıtı olmasına bağlanabilir $(2,13)$.

Pinto ve ark. (2) yapmış oldukları 11 hastalık çalışmada, dirençli epilepsi nedeni ile cerrahi geçiren hastaların 7'sinin patolojik preparatında; operasyon öncesi elde edilen kranial MRG tetkikinde tespit edilemeyen kortikal malformasyon saptamıştır. Net olmamakla birlikte, özellikle kortikal organizasyon bozukluklarının (şizensefali, giral malformasyon, polimikrogiri ve fokal kortikal disgenezi gibi) eşlik ettiği ciddi SWS vakaları, yaşamın daha erken dönemlerinde ortaya çıkan inatçı/tedaviye dirençli nöbetlerle ilişkili olabilir. Bu çalışmada en sık klinik bulgu literatür ile uyumlu olarak nöbet idi (\%46.66). Hastalarda eşlik eden kortikal malformasyon ya da migrasyon anomalisi saptanmadı. Bu bulgu bu çalışmadaki hastalarda dirençli epilepsi öyküsü olmamasını açıklayabilir. Ayrıca iki yaşından küçük çocuklarda tamamlanmamış myelinasyon da kortikal anomalilerin tanınmasını zorlaştırabilir.

SWS'da beyin parankiminde atrofi; nöronal hücrelerde kayıp, dejenerasyon, glial proliferasyon ve gliozisle ilişkili olarak izlenmektedir. Kalvaryal kalınlaşma, paranazal sinüsler ve mastoid hücrelerde genişleme, küçük hemikranyum kortikal atrofi ile ilişkili radyolojik bulgulardır. Atrofiye distrofik kalsifikasyonlar da eşlik eder. Bu çalışmada leptomeningeal anjiom tespit edilen bütün hastalarda literatür ile uyumlu olarak beyin parankiminde atrofi saptandı. Literatürde etkilenen hemisferde myelinasyon sürecinin normal hemisfere kıyasla daha hızlı olduğunu ve patolojik hemisferde akselere myelinasyonla uyumlu MRG bulguları olduğunu bildiren yayınlar mevcuttur. Akselere myelinasyonun hipoksi/iskemi ile ya da genişlemiş venüllerle ilişkili olarak hiperperfüzyona bağlı olduğu düşünülmüştür $(2,9)$. Ancak bu çalışmadaki hastalarda iki hemisfer arasında myelinasyon farkı ya da akselere miyelinasyon ile uyumlu olabilecek sinyal/dansite değişikliği saptanmadı.

Kontrast sonrası elde edilen T1A MRG pial anjiomatozis varlığını ve yaygınlığını kolaylıkla ortaya koyarken aynı zamanda anormal derin-yüzeyel venöz yapıları ya da eşlik edebilecek vasküler malformasyonları da saptamaktadır $(2,11,14,15)$. Ancak yenidoğan ve genç infantlarda duyarlıı̆ı azdır, bu nedenle ilk MRG'ı normal olan vakalarda bir yaşından sonra MRG tekrarlanmalıdır (13). Derin ve yüzeyel venöz sistem özellikle sentrum semiovale düzeyindeki kollaterallerle (transmedüller venler) birbirleri ile ilişkilidir. SWS de bu venler dilatedir ve yüzeyel venöz sistemdeki kanı derin venöz sisteme tașımaktadır[9]. Anormal genişlemiş venöz yapılar yüzeyel venlerde gelişen olası oklüzyonlar ve derin venöz sisteme ulaşan kollateraller ile ilişkili olabilir $(2,11)$. Juhasz C. ve ark. (11) göre SWS'de erken dönemde transmedüller kollateral venöz yapılar gelişmekte ve korteksi hasardan korumaktadır; kollateral venöz drenaj yetersiz kaldığında ise hasar ortaya çıkmaktadır. Ayrıca epilepsi nöbetleri ile birlikte parankimde enerji intiyacı artmakta, hipoksi gelişmekte ve beyin hasarı önlenememektedir $(9,11)$. FDG-PET (Functional neuroimaging with fluorodeoxyglucose-positronemission tomography) çalsşmaları patolojik kortikal alanda hipometabolizma olduğunu tespit etmiştir. Ancak kollateral venöz sistemle-hipometabolizma arasında bir ilişki olup olmadığı henüz bilinmemektedir $(9,11,16)$.

Manyetik duyarı MRG ( SWAN, GRE) kontrast maddeye intiyaç duymadan küçük vasküler yapılardaki deoksijenize kanı tespit edebilen bir yöntemdir. Konvansiyonel MRG incelemelerine kıyasla belirginleșmiş venöz yapıları daha kolaylıkla ortaya koyabilmektedir. MR venografide ve kontrastlı MRG de sıklıkla iyi gösterilemeyen ince venöz kollateraller hakkında anatomik detay vermektedir (9). Juhasz C. ve ark. (11) prospektif olarak yaptıkları çalışmada tek taraflı tutulumları olan 13 SWS hastasında transmedüller kollateral venöz yapıların manyetik duyarlı MRG ile 


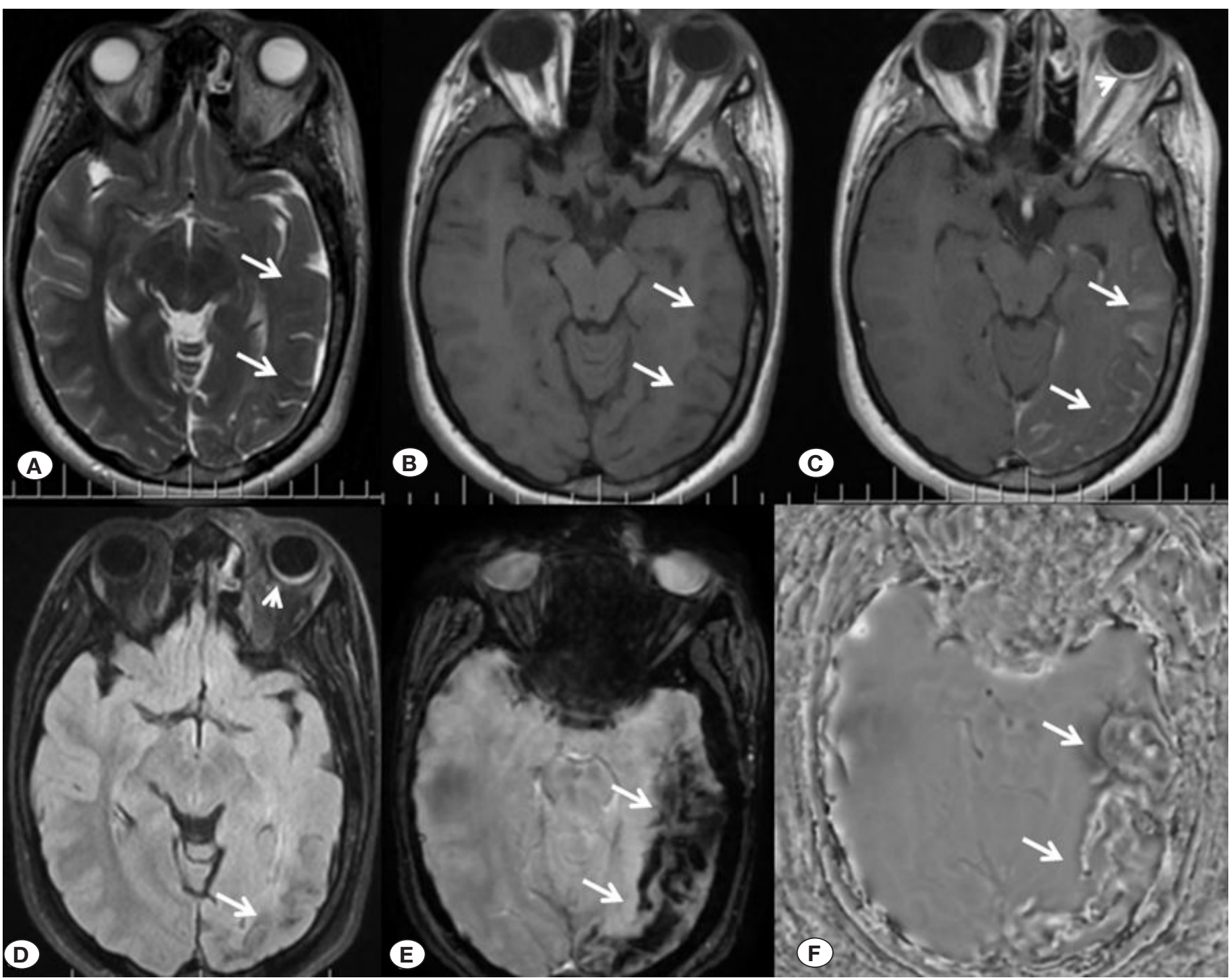

Şekil 1: 15 yaşında kız hasta, kranial MRG tetkikinde sol temporooksipitalde volüm kaybı ile birlikte aksiyel T2 (A) ağırlıklı, T1 (B) ağırlıklı ve FLAiR (D) görüntülerde silik hipointens sinyal değişiklikleri (oklar ), aksiyel kontrastlı T1 (C) ağırlıklı görüntülerde leptomeningeal kontrastlanma (oklar), manyetik duyarlı MRG (E) ve faz (F)görüntülerde kalsifikasyon alanları (oklar) izlenmektedir. Ayrıca sol gözde diffüz koroidal hemanjiomla uyumlu kalınlık artışı ve kontrastlanma mevcuttur (C,D okbaşları).

erken dönemde tespit edilebildiğini göstermişlerdir. Mikroyapısal beyaz cevher anomalilerinin kortikal patolojilere eșlik ettiğini ve bilișsel gelişimi etkileyebileceğini bildirmişlerdir. Bu nedenle konvansiyonel MRG tetkikine manyetik duyarlı MRG ve beyaz cevher yapısal bütünlüğünü daha kolay değerlendirmek için difüzyon tensör görüntüleme (DTI) incelemelerinin de eklenmesini önermişlerdir (11). Bizim de çalışmamızda 14 hastanın manyetik duyarlı MRG tetkiki de mevcuttu. Ancak hiçbir hastamızda DTI mevcut değildi. Bu çalışmada radyolojik bulgusu olan hastaların \%87.5'inde özellikle manyetik duyarlı MRG'de daha net ortaya çıkan transmedüller ve kortikal venlerde belirginleșme saptandı.

Ayrica manyetik duyarlı MRG serebral kalsiyum ve demir birikimine de hassas olup kalsifikasyonları belirlemekte duyarıdır $(11,17,18)$. Pili VK ve ark. (19) SWS'de kalsifikasyonların yaygın ve progresif olduğunu; özellikle erken epilepsi bașlangıcı olan vakalarda hızlı ilerlediğini göstermişlerdir. BT kalsifikasyonları göstermede MRG'ye kIyasla daha üstündür ancak yenidoğan ve infantlarda normal olabilir. Bu çalışmada BT tetkiki olan iki hastada da SWS için tipik giral/subkortikal kalsifikasyon paterni mevcuttu $(13,18)$. Fokal tutulumu olan bir hasta dışında tüm hastaların manyetik duyarlı MRG incelemerinde de kalsifikasyon saptandı. Biz de manyetik duyarlı MRG'nin kalsifikasyon ve genişlemiş venöz yapıların varlığını ve yaygınlığını belirlemede konvansiyonel MRG'ye üstün olduğunu düşünmekteyiz. Çalıșmamızda iki olguda kalsifikasyon odakları sadece manyetik duyarı MRG tetkikinde seçilebilmiştir.

Diffüzyon tensör MRG den türetilmiş ADC haritasının da erken SWS tanısında etkin olduğunu savunan yazarlar vardır. Düşük ADC değerleri azalmış diffüzyonu ișaret eder ve bu bulgunun SWS'nu erken tanımada ve hastanın prognozunu öngörmede 


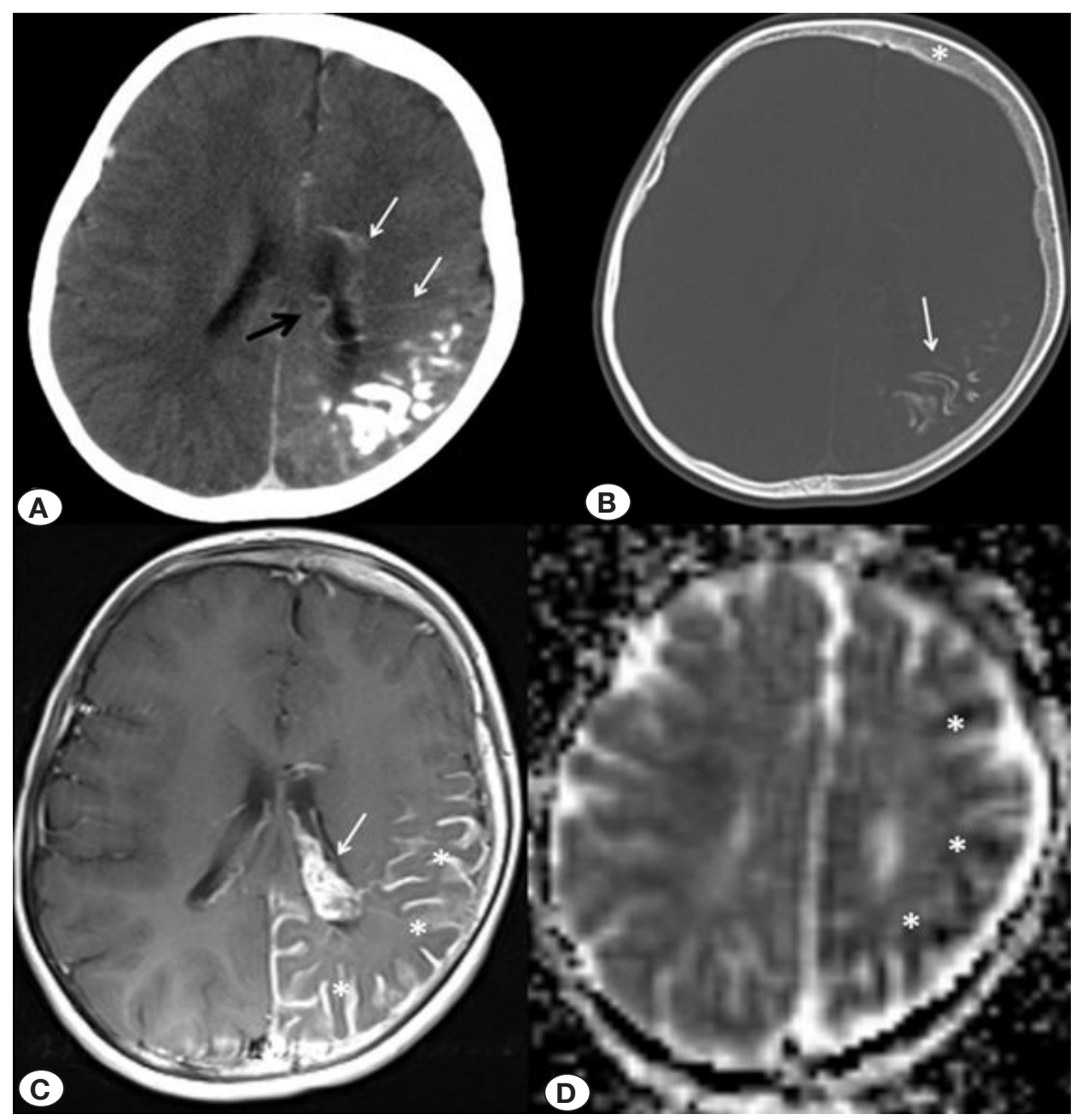

Şekil 2: 5 aylık erkek hasta, kontrastı aksiyel BT (A, yumuşak doku penceresi) tetkikinde transmedüller ve subependimal venöz yapılarda belirginleşme (beyaz ve siyah oklar) izlenmektedir. Aksiyel BT kemik penceresi (B) görüntüsünde tren rayı tarzında kalsifikasyon (beyaz ok) , solda kalvaryal kalınlaşma $\left(^{*}\right)$ ve sol küçük hemikranyum izlenmektedir. Kontrastlı aksiyel MRG (C) görüntüde sol koroid pleksusta genişleme (ok) ve leptomeningeal anjiomla uyumlu kontrastlanma (*) alanları mevcuttur. ADC haritasında (D) sol hemisfer simetriğine nazaran hipointensdir(*).

katkı sağladığı bildirilmiștir. Ancak pediatrik hastalarda yașa göre standardize edilmiș ADC değerleri mevcut değildir. Pinto ve ark. (8) 8 hastalık prospektif çalışmalarında azalmış ADC değerleri ile artmış nöbet riski arasında bağlantı olduğunu, bu bulgunun duyarlılık ve özgüllüğünü belirlemek için ek çalışmalara intiyaç olduğunu ifade etmişlerdir. Bu çalışmadaki hastaların ADC değerleri de karşı hemisferle kıyaslandığında düşüktü. Ancak hasta sayımızın az olması ve çekimlerin iki ayrı MR cihazında yapılmıș olması nedeni ile standart değerler belirlenemedi.

SWS'de glokom erken görme bozuklukları ile ilişkilidir. Glokom gelişme sıklığı \%40-60 olup hastaların \%60 ında 1 yaşından önce ortaya çıkar. Gözde ayrıca buftalmus,amliyopi, iris heterokromisi, strabismus, optik atrofi, ve genişlemiş retinal damarlar gibi anomaliler de görülebilir $(20,21)$. Canpolat ve ark. (12) 11 olguluk serilerinde vakaların yaklaşık yarısında glokom saptamışlardır. Bu çalışmada 2 hastada glokom mevcut olup olgularda ek göz anomalisi saptanmamıştır; bu bulgu hasta sayısının kısıtı olması ile ilişkili olabilir.
SWS da retina genellikle normal olmakla birlikte fasiyal ve leptomeningeal anjiomların yanında retinal hemanjiomlar da görülebilir (22). Anjiomlar yüzle birlikte vücudun diğer bölgelerinde (dudak, ense, boyun, gövde, ekstremiteler...) de görülebilmektedir (12). Bu çalışmada bir olguda yüzle birlikte dudak ve temporal bölgeye uzanan anjiom, bir olguda dudağa, bir olguda boyun ve temporal bölgeye uzanan, bir olguda ise yüzle birlikte üst ekstremitede de izlenen anjiom, bir hastada ise tek taraflı diffüz koroidal hemanjiom mevcuttu.

Hastaların bilişsel gelişimleri ise ilk nöbet yaşı ve ilaca dirençli nöbet birlikteliği ile ilişkilidir. Nöbet geçirmemiş çocuklar genellikle normal bir psikomotor gelişime sahipken, hastaların yaklaşık \%50-60'ında psikomotor gelişme geriliği veya mental reterdasyon görülür $(1,2)$. Tek taraflı fokal tutulumlarda bile bilişsel gelişim şaşırtıcı bir şekilde kötü olabilmektedir. Bu nedenle eşlik eden kortikal malformasyonların ya da fonksiyonel anomalilerin psikomotor gelişim sürecinde etkili olduğu düşünülebilir (11). Bu nedenle SWS hastalarının erken dönemde özellikle presemptomatik olduğu dönemde tanı alması ailelerin 
eğitilmeleri, hastaların tıbbi olarak takibe girmeleri ve profilaktik tedavi açısından önemlidir $(1,2)$.

Illaca dirençli ve kontrol edilemeyen epilepside fokal kortikal rezeksiyon, hemisferektomi veya kallozotomi gibi cerrahi tedaviler seçenek olabilir. Pinto ve ark. dirençli epilepsi öyküsü olan 7 hastalık serilerinde epilepsi cerrahisi uygulamışlar ve hastalarının nöbetsiz olarak yaşamlarına devam ettiğini; bilateral tutulum olsa bile dirençli nöbet öyküsü olan hastalarda cerrahinin tedavi seçeneği olabildiğini bildirmişlerdir (2). Steinbok ve ark. (23) ise toplamda 8 merkezden yayınladıkları 116 hastanın \%82 sinin yaşamın ilk yılında nöbetle bulgu verdiğini, 3 yașından önce yapılan epilepsi cerrahisinin güvenli olduğunu, nöbet kontrolünde etkili olduğunu ve psikomotor gelişimi desteklediğini bildirmişlerdir $(1,2)$. Bu çalışmadaki hasta grubunda ilaca dirençli olup kontrol altına alınamayan ya da cerrahi tedavi uygulanan hasta mevcut değildi. Sadece bir hastada (\%6.66) psikomotor gerilik mevcuttu; bu bulgu hastalarımızın nöbetlerinin ilaca dirençli olmaması ile açıklanabilir.

Çalışmamızın bazı limitasyonları mevcut olup görece az hasta sayısı ile yapılmış retrospektif bir çalışmadır. Çalışmaya dahil edilen hastaların, bir hasta dışında, genetik tanısı olmaması çalışmamızın diğer bir sınırılığıdır. Çalışma retrospektif olarak planlandığı için hastaların klinik bulgularına dosya arşivinden ulaşılması ve bazı bilgilere ulaşılamaması da limitasyon olarak kabul edilebilir. Ayrıca, sadece iki hastamızda BT tetkiki mevcuttur, bu nedenle BT ve MR tetkiki lezyon saptama yeteneği açısından karşılaştırılamamıştır. BT ve MRG bulgularının karşılaştırılabileceği daha fazla sayıda hasta ile yapılacak araştırmalar ya da ileri MR uygulamalarının kullanıldığı prospektif çalışmalar özellikle erken tanı ve ek anomalilerin tespiti açısından faydalı olabilir.

Sonuç olarak, SWS genellikle yaşamın ilk yılında nöbetle ortaya çıkan tipik radyolojik bulguları olmakla birlikte, adolesan çağda baş ağrısı gibi daha nadir bulgularla da semptom verebilen nadir bir sendromdur. SWS'de kontrastlı MRG tanı koymak ve bulguların yayıımını belirlemek için anahtar rol oynamaktadır. Manyetik duyarlı MRG kalsifikasyonların saptanmasında, erişkine kıyasla radyasyona daha duyarlı olan çocuk hastalarda, BT tetkiki yerine tercih edilebilir; ek olarak kollateral/genişlemiş venöz yapıların tespitinde de etkilidir.

\section{Finansal Kaynak}

Bu çalışma sırasında, yapılan araştırma konusu ile ilgili doğrudan bağlantısı bulunan herhangi bir ilaç firmasından, tıbbi alet, gereç ve malzeme sağlayan ve/veya üreten bir firma veya herhangi bir ticari firmadan, çalışmanın değerlendirme sürecinde, çalışma ile ilgili verilecek kararı olumsuz etkileyebilecek maddi ve/veya manevi herhangi bir destek alınmamıştır.

\section{Çıkar Çatışması}

Bu çalışma ile ilgili olarak yazarların ve/veya aile bireylerinin çıkar çatışması potansiyeli olabilecek bilimsel ve tıbbi komite üyeliği veya üyeleri ile ilişkisi, danışmanlık, bilirkişilik, herhangi bir firmada çalışma durumu, hissedarlık ve benzer durumları yoktur.

\section{KAYNAKLAR}

1. Bar C, Pedespan JM, Boccara O, Garcelon N, Levy R, Grévent D, et al. Early magnetic resonance imaging to detect presymptomatic leptomeningeal angioma in children with suspected Sturge-Weber syndrome. Dev Med Child Neurol 2019: doi:10.1111/dmcn.14253.

2. Pinto AL, Chen L, Friedman R, Grant PE, Poduri A, Takeoka M, Prabhu SP, Sahin M. Sturge-Weber Syndrome: Brain Magnetic Resonance Imaging and Neuropathology Findings. Pediatr Neurol 2016;58:25-30.

3. Shirley MD, Tang H, Gallione CJ, Baugher JD, Frelin LP, Cohen $B$, et al. Sturge-Weber syndrome and port-wine stains caused by somatic mutation in GNAQ. N Engl J Med 2013;368:1971-9.

4. Nakashima $M$, Miyajima $M$, Sugano $H$, limura $Y$, Kato $M$, Tsurusaki $Y$, et al. The somatic GNAQ mutation c.548G $>A$ (p.R183Q) is consistently found in Sturge-Weber syndrome. J Hum Genet 2014;59:691-3.

5. Balkuv E, Isik N, Canturk IA, Isik N, Basaran R. Sturge-weber syndrome: a case report with persistent headache. Pan Afr Med J 2014;18:87.

6. Ergün R, Okten Al, Gezercan Y, Gezici AR. Sturge-Weber syndrome accompanied with multiple congenital intracranial lesions. Acta Neurochir (Wien) 2007;149:829-30.

7. Comi AM. Presentation, diagnosis, pathophysiology, and treatment of the neurological features of Sturge-Weber syndrome. Neurologist 2011;17:179- 84.

8. Pinto ALR, Ou Y, Sahin M, Grant PE. Quantitative Apparent Diffusion Coefficient Mapping May Predict Seizure Onset in Children With Sturge-Weber Syndrome. Pediatr Neurol 2018;84:32-38.

9. Jacoby CG, Yuh WT, Afifi AK, Bell WE, Schelper RL, Sato Y. Accelerated myelination in early Sturge-Weber syndrome demonstrated by MR imaging. J Comput Assist Tomogr 1987;11:226-31.

10. Nakata Y, Yagishita A, Tsuchiya K. Imaging of Sturge-Weber syndrome: cranial CT and MR findings. Nihon Igaku Hoshasen Gakkai Zasshi 2004;64:210-5.

11. Juhász C, Haacke EM, Hu J, Xuan Y, Makki M, Behen ME, Maqbool M, Muzik O, Chugani DC, Chugani HT. Multimodality imaging of cortical and white matter abnormalities in Sturge-Weber syndrome. AJNR Am J Neuroradiol 2007;28:900-6.

12. Canpolat $M$, Per Hüseyin, Yıkılmaz A, Gümüş $H$, Özcan $A$, Poyrazoğlu HG, ve ark. Sturge-Weber sendromu; klinik ve radyolojik değerlendirme. Gaziantep Med J 2013:19;30-4.

13. Comi AM. Sturge-Weber syndrome. Handb Clin Neurol 2015;132:157-68.

14. Nabbout R, Juhasz C. Sturge-Weber syndrome. Handb Clin Neurol 2013;111:315-21.

15. Fogarasi A, Loddenkemper T, Mellado C, Tuxhorn I, Evers G, Sarco D, et al. Sturge-Weber syndrome: clinical and radiological correlates in 86 patients. Ideggyogy Sz 2013;66:53-7.

16. Lee JS, Asano E, Muzik O, Chugani DC, Juhász C, Pfund Z, et al. Sturge-Weber syndrome: correlation between clinical course and FDG PET findings. Neurology 2001;57:189-95

17. Mentzel HJ, Dieckmann A, Fitzek C, Brandl U, Reichenbach JR, Kaiser WA. Early diagnosis of cerebral involvement in SturgeWeber syndrome using high-resolution BOLD MR venography. Pediatr Radiol 2005;35:85-90. 
18. Gumus K, Koc G, Doganay S, Gorkem SB, Dogan MS, Canpolat M, et al. Susceptibility-Based Differentiation of Intracranial Calcification and Hemorrhage in Pediatric Patients. J Child Neurol 2015;30:102936.

19. Pilli VK, Behen ME, Hu J, Xuan Y, Janisse J, Chugani HT, Juhász C. Clinical and metabolic correlates of cerebral calcifications in Sturge-Weber syndrome. Dev Med Child Neurol 2017;59:952-8.

20. Piram M, Lorette G, Sirinelli D, Herbreteau D, Giraudeau B, Maruani A. Sturge-Weber syndrome in patients with facial port-wine stain. Pediatr Dermatol 2012; 29: 32-7.
21. Sujansky E, Conradi S. Sturge-Weber syndrome: age of onset of seizures and glaucoma and the prognosis for affected children. $J$ Child Neurol 1995; 10: 49-58.

22. Ratra D, Yadav H, Dalan D, Sodhi PKS, Ratra V. Retinal vascular abnormalities in Sturge-Weber syndrome. Indian J Ophthalmol 2019;67:1223-6.

23. Steinbok P, Gan PY, Connolly MB, Carmant L, Barry Sinclair D, Rutka J, Griebel R, Aronyk K, Hader W, Ventureyra E, Atkinson J. Epilepsy surgery in the first 3 years of life: a Canadian survey. Epilepsia 2009; 50:1442-9. 